\title{
Behavioural culpability for traffic accidents
}

\author{
L. Dorn* \& A. E. af Wåhlberg \\ School of Aerospace, Transport and Manufacturing, \\ Cranfield University, Cranfield, Bedfordshire, MK43 0AL, UK
}

\section{* Corresponding author}

\begin{abstract}
This study presents a description of the concept of behavioural culpability, a step-by-step manual for using it, and an empirical test of a suspected mis-classification of culpability. Behavioural culpability is defined as whether the driver's actions contributed to a crash and that non-culpable crashes are not caused by any specific behaviour and can only be predicted from exposure. Drivers with non-culpable crashes are therefore a random sample of the population. However, if the criteria for culpability and/or the individual judgements are not reflective of the principle of behavioural culpability, no fault drivers will not be a random sample of the driving population. To test the predictions from the definition of randomness in a sample assumed to have sub-optimal coding, the categorization of crash involvement undertaken by a British bus company was tested for associations between at fault and no fault crashes, age and experience. As predicted from the low percentage of at fault accidents in the sample, correlations between the variables indicated that a fair percentage of at fault crashes had been coded as no fault of the bus driver, suggesting a too lenient criterion. These results show that within fleetbased companies, culpability for a crash is probably allocated for legal reasons, which means that the predictability of accident involvement taking into account individual differences is not fully utilized. The aim of behavioural culpability coding is to increase effect sizes in individual differences in safety research and to improve our capability of predicting accident involvement.
\end{abstract}

Key words: bus driver, accident, crash, culpability, fault 


\section{Introduction}

The most common method used to predict individual differences in road crash involvement is to lump together all kinds of traffic accidents into a single category which is then used as a dependent variable (af Wåhlberg, 2003; 2009). At the same time, there are also numerous studies which have used categorization of crashes. These studies separate them into different groups depending upon their characteristics and use these categories as dependent variables. Sometimes, certain crashes are simply deleted, while at other times two parallel variables are formed. Minor and major crashes is one such example. However, the most common type of categorization refers to the driver's action in terms of causality. One group of crashes are those which the driver was involved in causing, while the other are those where the driver's actions did not contribute to the incident (e.g. Council, Harkey, Khattak \& Mohamedshah, 2003; Vujanic, Antic, Pesic \& Savicevic, 2016). This distinction has been called a number of names; at fault, blameworthy, responsible, active-passive, preventable and culpable are some of the terms used (see the review in af Wåhlberg, 2009). Although explicit definitions and discussions of these variables are scarce, it can be concluded that they share a reason for the categorization.

When individual differences in safety are to be predicted, non-culpable crashes are actually error variance from the perspective of most predictors, because they are not caused by any specific behaviour. They can only be predicted from exposure. It can therefore be concluded that one of the reasons why effect sizes for differences in accident record are usually small (Vaa, 2014; af Wåhlberg, Barraclough \& Freeman 2015; 2016) is because non-culpable crashes have not been deleted from the dependent variable. This is the central tenet of the idea of behavioural culpability (af Wåhlberg, 2003; 2009; af Wåhlberg \& Dorn, 2007).

Behavioural culpability can be defined as whether the driver's actions contributed to the crash. This make it conceptually different from ideas such as the active-passive distinction by West (1997; see the discussion in af Wåhlberg, 2002), and the concept of legal culpability as used by transportation companies and police (i.e. legal culpability is judged mainly by whether the driver has broken a traffic law). A company can be expected to be motivated to avoid their crashes being categorized as blameworthy to reduce legal costs.

From the perspective of behavioural culpability therefore, it can be suspected that most categorizing into fault-not at fault etc. has been sub-optimal. That is, if the goal is to predict accident involvement, the coding has not been correct. Behaviourally culpable crashes have probably been coded as non-culpable. This conclusion can be reached by comparing the percentages of each crash category across studies (af Wåhlberg, 2009). For reasons which will be described below, in most studies, the percent culpable crashes is probably much too small. Furthermore, none of the studies using causality-based categorization has tested whether the coding is correct, probably because up until 2007 no such method was available (af Wåhlberg \& Dorn, 2007; see also af Wåhlberg, 2008; 2009). Thereafter, some papers have coded for culpability and referred to the concept of behavioural culpability, but without applying the actual tests recommended (e.g. Asbridge, Brubacher \& Chan, 2013; Cooper, Meckle \& Andersen, 2010; Curry, Pfeiffer \& Elliott, 2017; Curry, Pfeiffer, Myers, Durbin \& Elliott, 2014; Goh et al., 2014) ${ }^{1}$. In essence, the inherent power in the suggested concept and method has not been utilised (for example in evaluation studies; af Wåhlberg, 2018), apparently because it has not been understood (e.g. Salmi, Orriols \& Lagarde, 2014).

As noted, the principle of behavioural culpability has not been applied, even in studies where the authors apparently share the belief in the underlying process that crashes should be categorized differently and drivers in non-culpable crashes are a random sample of the driving population. To facilitate the application of behavioural culpability coding in research, a

\footnotetext{
${ }^{1}$ Excluding papers on induced exposure, as the method suggested here need a known population of drivers.
} 
practical guide for its implementation has been constructed (and presented in the Appendix). In short, it describes an iterative process of coding, where the coder learns to adjust the criterion for behavioural culpability until the data meets the requirements.

Behavioural culpability adopts the main assumption of induced exposure (e.g. Carr, 1969), that drivers in non-culpable crashes are a random sample of the driving population (Chandraratna \& Stamatiadis, 2009). This assumption is then turned into a hypothesis which can be tested. So, instead of assuming that drivers with crashes which have been coded as non-culpable are a random sample of the driving populations, this is tested in a number of ways. If this goal is achieved (randomness of non-culpable drivers), then by default the remaining crashes should be culpable. This approach assumes that more than one driver in a crash can be (partly) responsible for the crash. For induced exposure, it is usually assumed that only one driver is responsible (e.g. Jiang \& Lyles, 2010), an assumption for which there is no supporting evidence.

The random sample criterion as defined here creates several predictions, which can be used for testing the correctness of the coding. First, culpable and non-culpable crash involvements should not correlate within the individual, when exposure has been controlled for. This is because they arise from different mechanisms (the actions of the driver versus mere exposure).

Second, any variable known to have an association with all crash involvements should have a stronger correlation with culpable crash involvement, and none at all with non-culpable ones. The only exception is exposure to risk, which should have a stronger correlation with nonculpable crashes. As a special case of this general rule, it can be observed that drivers with only non-culpable crashes should be similar to drivers with no crash involvements ${ }^{2}$. Third, culpable crashes should correlate within drivers between time periods (with a strength which is dependent on the variable means; af Wåhlberg, 2009), while non-culpable crashes should not (when exposure is controlled).

These effects should be present in the analyses when coding is correct. If not, the size of the deviance from what can be predicted using this method indicates the percent of crash involvements that are in the wrong category for culpability. This means that the degree of deviance can be compared with the percent of crash involvements coded as culpable across samples. If the distinction between culpable and non-culpable crash involvement is correct (but coding is slightly off the mark), the effects should increase with the percentage of culpable crash involvement in the sample, until a maximum is reached, and then decline. This prediction is based upon the simple assumption that a certain criterion for culpability will be too lenient (culpable crash coded as non-culpable crash), or too harsh (non-culpable crash coded as culpable crash), while random errors are small.

If the simplifying assumption is erroneous, meaning that humans have difficulties grasping the causation factors for crashes and make random errors in their judgements, then the predictive peak will be reached anyway (but will not be optimal). However, the correlation between culpable and non-culpable crash involvement within drivers will still be above zero when exposure has been controlled for. This latter criterion for correctness of coding is therefore the most important one.

This optimal point must reside somewhere between 50 and 100 percent culpable crash involvements, that is out of all cases of crash involvement at least fifty percent must be judged as culpable. The starting point of fifty percent is due to the fact that most traffic accidents (but not involvements) are partly due to some aspect of driver behaviour (figures of 90-95 percent

\footnotetext{
${ }^{2}$ All these comparisons will be more exact as the time period used for calculations increase. This is especially so for the groups of drivers with no crashes and non-culpable crashes only, respectively. A very short time period will not separate the truly safe from the lucky ones who have not yet crashed, despite their risky behaviour.
} 
are often referred to - see Sabey \& Taylor, 1980). Therefore, at least half the drivers involved must be culpable, but less than a hundred percent.

The concept of behavioural culpability is difficult to test for validity, because there is no independent method of coding for culpability. This means that deviations from predictions, for example that non-culpable drivers will be similar to the driving population, cannot be decisively attributed to erroneous coding, but could just as well be due to a fault in the concept. However, the prediction of an optimal predictive power somewhere between fifty and a hundred percent is testable, as no rival explanation would seem to be present (a prediction from restriction of variance would predict a monotonous decline in effect size). This prediction can be tested within a sample, using different coding rules and comparing the predictive power resulting from these, or meta-analytically between samples.

Differences in exposure between participants are almost always a problem in road user studies, and need therefore to be controlled for when using behavioural culpability coding. However, this can be done in different ways and using different measures of exposure. The main contenders would seem to be mileage and time driving, but Chipman, MacGregor, Smiley and Lee-Gosselin $(1992 ; 1993)$ found that differences between crash risk estimates using these two measures were rather small, with time spent driving tending to have the stronger association with crashes. Similar results have been reported by Dionne, Desjardins, Laberge-Nadeau and Maag (1995). In principle, induced exposure methods can be applied too, but only at a group level.

This paper aims to present a more detailed description of the concept of behavioural culpability, and the predictions which can be made to assist further research in this field. The empirical part of this study was intended to show what will happen when fault is not assigned according to behavioural culpability. Deviations from the predictions will indicate that some other approach or criterion has been used. This principle will be illustrated in the present study using data from a bus company. Here, it can be suspected that company officials judging the drivers' culpability will mainly have coded crashes using legal culpability as a criterion. Although this would probably to a large degree overlap with the behavioural culpability perspective, differences in results can still be expected when testing the assignment of culpability.

\section{Method}

\subsection{General}

The study was undertaken using crash data supplied by a British bus company for the evaluation of a bus simulator (a different bus company to the one used in the original study by af Wåhlberg \& Dorn, 2007). At the time of the study, the bus company served Greater London with over 6,800 scheduled buses operating on over 700 different routes. Over the year the bus company made over 1.8 billion passenger journeys across London. The majority of buses in London are double decker measuring between 9.5 metres and 11.1 metres long weighing approximately 7 ton empty and 12 ton when full of passengers.

\subsection{Data}

Data was available for the time period 2006-2008 and included a number of at fault and no fault crashes $^{3}$ (collisions with other objects) per driver, as judged by company officials. Date of birth, current full time or part time employment (there was no information about whether this had changed during the period of interest) and the driver's length of service (years of experience) were also available. The latter two were the only variables available which could

\footnotetext{
${ }^{3}$ This terminology is similar to that of our definition of behavioural culpability, but was probably used to determine legal responsibility by the company. In the results, the company's terms will be used.
} 
be used as predictors. Experience is reliably, although weakly, associated with crash involvement (e.g. Blom, Pokorny \& van Leeuwen, 1987; Häkkinen, 1979; Peck, 1993) and therefore a good variable to use in the kind of tests undertaken here. Age usually has a very weak or even non-existent association with crashes (Dorn \& af Wåhlberg, 2008), and any differences in associations with culpable and non-culpable crashes are therefore difficult to evaluate.

Only data for full time drivers who had worked complete years were used in the present analysis, to hold exposure to risk constant. Whilst mileage would possibly be preferable as a measure of exposure, this information was not available to us. Furthermore, for bus drivers driving in similar areas, the correlation between hours and mileage should be very high, as the timetables restrict their speed.

\subsection{Overview}

To determine whether or not the bus company assignment of culpability meets the requirements for behavioural culpability, crashes deemed to be no fault of the bus drivers did have the characteristics of a random process. Specifically, the following effects were tested. First, at fault and no fault crashes should be unrelated within drivers when exposure has been controlled for. Second, drivers who have no fault crashes should be similar to no-crash drivers, but different from the population, on variables known to be associated with crash involvement. Third, events which are random should not correlate within individuals between time periods (i.e. some drivers should not consistently have more no fault crashes), when exposure is controlled for.

\subsection{Analysis}

The analysis aimed to estimate how well effect sizes from the company's crash data coding for culpability agrees with the theoretically derived predictions outlined above, given the percentage of at fault crashes in the sample. Therefore, the bi-variate associations between the fault and no fault crash variables, age and experience were calculated with driver as the unit of analysis. These associations were computed for the whole time period, and for each yea rin isolation. Furthermore, drivers with no fault crashes only were compared to those with no crashes, and drivers with fault crashes, on mean values of age and experience.

Three different statistical methods were used; Pearson correlations for associations between variables, and Cohen's d and t-tests for defined groups. These statistics might not be the optimal tools for skewed data like crashes, but the aim of the analysis was to compare the sizes of effects between groups/variables, not necessarily to estimate a true effect size. In social science research, the meaning of an exact effect size is most often not clear. If a prediction of a positive association is made, any positive correlation will be cited as positive evidence, however miniscule. When testing coding for culpability, it would therefore be useful to have a criterion against which to evaluate the findings. It is therefore suggested that the benchmarks of Cohen will be useful (Cohen's d: small $=.20$; medium $=.50$; large $=.80$; Pearson's correlation $(\mathrm{r})$ : small $=.10$; medium $=.30$; large $=.50$ ). Applying this to the prediction of a zero correlation between culpable and non-culpable crash involvements, an actual correlation of .25 would indicate a medium problem with the coding.

Table 1 Descriptive statistics for the sample, with crash involvements (number of crashes per driver per year) for the period 2006-2008. Only full-time drivers are included. N=2277 drivers. 


\begin{tabular}{|l|l|l|l|l|l|l|l|}
\hline Variable & Mean & Median & Variance & $\begin{array}{l}\text { Standard } \\
\text { deviation }\end{array}$ & Min-max & Skewness & Kurtosis $^{5}$ \\
\hline All crashes & 2.91 & 2.00 & 6.21 & 2.49 & $0-18$ & 1.49 & 3.56 \\
\hline At fault crashes & 1.29 & 1.00 & 2.01 & 1.42 & $0-10$ & 1.51 & 3.20 \\
\hline No fault crashes & 1.63 & 1.00 & 2.93 & 1.71 & $0-15$ & 1.90 & 6.52 \\
\hline Age 2007-06-30 & 44.3 & 43.8 & 93.8 & 9.69 & $\begin{array}{l}21.6- \\
69.5\end{array}$ & 0.17 & -0.65 \\
\hline $\begin{array}{l}\text { Experience } \\
\begin{array}{l}\text { 2007-06-30 } \\
\text { years) }\end{array}\end{array}$ & 6.83 & 5.06 & 31.5 & 5.61 & $\begin{array}{l}1.52- \\
43.26\end{array}$ & 2.75 & 9.63 \\
\hline
\end{tabular}

\section{Results}

\subsection{Descriptives}

First, descriptive statistics were computed (Table 1). Here, it can be seen that only forty-four percent of all crash involvements were deemed by the company to be the bus drivers' fault. The crash involvement variables had fairly good distributions for such data; the number of drivers with no crash involvements was smaller than the number with one involvement, and the standard deviations were close to the means.

\subsection{Testing correlation between culpable and non-culpable crashes}

If no fault crashes are randomly distributed among drivers with equal exposure, they should have no association with at fault crashes. Therefore, associations between the study variables were computed (Table 2). If the criterion and coding is correct, there should be no correlation between culpable and non-culpable crash involvements. Correlations of any size indicate erroneous coding. Non-culpable crash involvements should not correlate with any predictor when exposure has been controlled for (either as crashes/exposure unit or in a partial correlation). If they do, this indicates erroneous coding of culpable crashes as non-culpable, to a degree according to Cohen's benchmarks.

As could be expected from the high percentage of no fault crash involvements, there was a correlation between no fault and at fault crash involvements. The correlations with age and experience will be treated in the next section.

Table 2 Pearson correlations between total number of crashes, at fault and not at fault crashes for the period 2006-2008, and bus driver age and experience. $\mathrm{N}=2277$ drivers.

\begin{tabular}{|l|l|l|l|l|}
\hline Variable & All crashes & At fault crashes & No fault crashes & Driver Age (years) \\
\hline At fault crashes & $.749^{* * *}$ & & & \\
\hline
\end{tabular}

\footnotetext{
${ }^{4}$ The formula for skewness (deviation of the distribution from symmetry): $n^{*} M_{3} /\left[(n-1) *(n-2) * \sigma^{3}\right]$

$\mathrm{M}_{3} \quad$ is equal to: $\Sigma\left(\mathrm{x}_{\mathrm{i}}-\mathrm{Mean}_{\mathrm{x}}\right)^{3}$

$\sigma^{3} \quad$ is the standard deviation (sigma) raised to the third power

$\mathrm{n} \quad$ is the valid number of cases.
}

${ }^{5}$ The formula for kurtosis (peakedness of the distribution): $\left[n *(n+1) * M_{4}-3 * M_{2} * M_{2} *(n-1)\right] /$ $\left[(n-1) *(n-2) *(n-3) * \sigma^{4}\right]$ where:
$\mathrm{M}_{\mathrm{j}} \quad$ is equal to: $\Sigma\left(\mathrm{x}_{\mathrm{i}}-\mathrm{Mean}_{\mathrm{x}}\right)^{\mathrm{j}}$
$\mathrm{n} \quad$ is the valid number of cases
$\sigma^{4} \quad$ is the standard deviation (sigma) raised to the fourth power 


\begin{tabular}{|l|l|l|l|l|}
\hline No fault crashes & $.836^{* * *}$ & $.262^{* * *}$ & & \\
\hline Driver Age (years) & .000 & $.085^{* * *}$ & $-.071^{* * *}$ & \\
\hline $\begin{array}{l}\text { Driver Experience } \\
\text { (years) }\end{array}$ & $-.074^{* * *}$ & $-.046^{*}$ & $-.069^{* * *}$ & $.433^{* * *}$ \\
\hline
\end{tabular}

$* \mathrm{p}<.05, * * * \mathrm{p}<.001$

\subsection{Testing group differences between drivers with different kinds of crashes}

If no fault crashes are due to a random process, they should be randomly distributed over all drivers with equal exposure. It could this happen that drivers who are actually safe have a no fault crash. However, as this has nothing to do with their behaviour, they should be behaviourally similar to drivers with no crashes. A proxy variable for safety behaviour is experience (e.g. Besharati \& Kashani, 2018; Pelz \& Schuman, 1971), and possibly age. Therefore, drivers with no crashes (proven safe), drivers with no fault crash involvements (presumably safe) and drivers with culpable crash involvements, were compared on the variables age and experience. It can be seen in Table 3 that both crash groups showed effects for mis-classification of crash involvement. However, the effects for the age variable are difficult to interpret, as age did not correlate with all crashes. Experience, on the other hand, has the expected effect of a fair difference between safe drivers (no crashes) and at fault, a difference which is not dependent upon coding reliability. The slight difference between no fault and at fault, on the other hand, must be due to erroneous coding.

The correlations for age and experience with crash variables in Table 2 show the same kind of effect. No fault crashes should have no association with any of these variables, while the correlation for fault should be somewhat stronger than the one for all crashes.

Table 3 The differences in age and experience between three groups of drivers; those with no crash involvements 2006-2008, those with no fault crash involvements only, and those with fault crash involvements within this time period. Results of independent t-tests and Cohen's d for differences between these groups are presented. Only drivers who worked for the whole period of 2006-2008 included.

\begin{tabular}{|l|l|l|l|l|l|l|}
\hline \multicolumn{3}{|l|}{} & \multicolumn{2}{l|}{ Mean (standard deviation) } & \multicolumn{2}{l|}{ Independent t-test / Cohen's d } \\
\hline Variables & $\begin{array}{l}\text { No crashes } \\
\text { (N=313 } \\
\text { drivers) }\end{array}$ & $\begin{array}{l}\text { No fault only } \\
\text { N=509 } \\
\text { drivers) }\end{array}$ & $\begin{array}{l}\text { At fault } \\
\text { (N=1455 } \\
\text { drivers) }\end{array}$ & $\begin{array}{l}\text { No crashes/ } \\
\text { crashes/ } \\
\text { No fault }\end{array}$ & $\begin{array}{l}\text { No fault/ At fault } \\
\text { fault }\end{array}$ \\
\hline $\begin{array}{l}\text { Driver Age } \\
\text { (years) }\end{array}$ & $44.4 / 10.4$ & $43.4 / 9.3$ & $44.6 / 9.6$ & $1.44 / 0.10$ & $-0.27 / 0.02$ & $-2.39 * / 0.13$ \\
\hline $\begin{array}{l}\text { Driver } \\
\text { Experience } \\
\text { (years) }\end{array}$ & $9.15 / 6.15$ & $8.30 / 5.49$ & $8.19 / 5.51$ & $2.07 * / 0.15$ & $2.74 * * / 0.16$ & $0.38 / 0.02$ \\
\hline
\end{tabular}

$* \mathrm{p}<.05, * * \mathrm{p}<.01$

\subsection{Comparing correlations for culpable and non-culpable crashes in different time periods} If no fault crashes are due to a random process, they should not correlate within drivers between years. Fault crashes, on the other hand, are due to a systematic process (accident proneness of individual drivers; af Wåhlberg, 2009), and should therefore correlate between years. The mean correlation between at fault crash involvements between years 2006 - 2007, 2006 - 2008, and 2007 - 2008 was .163 across years, .204 between no fault, and 121 inbetween these categories within years (the last is the same test as in 3.1). This can be contrasted with the expectation of no association between years for no fault crash involvements. At fault crash involvements on the other hand, should have a sizeable correlation between years, under the assumption of correct coding for behavioural culpability. As the correlations between years for no fault were larger than those for at fault, this indicates a severe problem in coding. 
Finally, the average correlation for all crashes between years was .273. If at fault crashes had been correctly coded for behavioural culpability, the inter-year association for these would have been even stronger.

Table 4 Pearson correlations between number of at fault and not at fault crash involvements for each of the years 2006-2008, for drivers who worked this whole period. $\mathrm{N}=2277$ drivers.

\begin{tabular}{|l|l|l|l|l|l|}
\hline Variable & At fault 2006 & No fault 2006 & At fault 2007 & No fault 2007 & At fault 2008 \\
\hline No fault 2006 & $.167^{* * *}$ & & & & \\
\hline At fault 2007 & $.184^{* * *}$ & $.130^{* * *}$ & & & \\
\hline No fault 2007 & $.164^{* * *}$ & $.240^{* * *}$ & $.123^{* * *}$ & & \\
\hline At fault 2008 & $.157^{* * *}$ & $.087^{* * *}$ & $.144^{* * *}$ & $.103^{* * *}$ & \\
\hline No fault 2008 & $.124 * * *$ & $.194^{* * *}$ & $.095^{* * *}$ & $.172^{* * *}$ & $.045^{*}$ \\
\hline
\end{tabular}

${ }^{*} \mathrm{p}<.05,{ }^{* * *} \mathrm{p}<.001$

\section{Discussion}

\subsection{Results}

The results of the analysis support the hypothesis that the bus company have not assigned culpability on the basis of whether the drivers have contributed to the crashes. Also, it suggests that there exist a systematic relationship between the percentage of culpable accidents and the associations between variables related to this, although this need to be specifically tested in a meta-analysis. It is apparent from the results that fleet-based companies use a legal definition of culpability, which yields different results from behavioural culpability coding. The latter type aims to optimally identify accident-prone drivers, while the former is mainly a method for settling insurance claims.

\subsection{Previous and current use of culpability in traffic safety research}

The general idea that only culpable crashes are meaningful as an outcome variable in traffic safety studies is not new (see the review in af Wåhlberg, 2009). However, those few researchers who have taken an interest in categorization by culpability have often concluded that it does not work as expected (e.g. Peck, 1993), apparently with the expectation being that culpable crashes should have larger effects than all crashes. But those conclusions have been based on data where behavioural culpability has probably been seriously underestimated, and categorization therefore has largely been erroneous. It should also be noted that the categorization of crash involvement into culpable and non-culpable cannot be absolutely certain in any specific case but testing and adjusting the criterion for culpability used can optimize the coding in a sample.

Jiang and Lyles (2010) discussed the problems of correctly assigning culpability, as well as the lack of correspondence between results of induced exposure and mileage measures. These authors used the method of comparing drivers in three-or-more-vehicle crashes with the standard two-vehicle approach of induced exposure. The argument was that if the nonresponsible parts in these sets were similar, they were probably a random sample of the population. However, this methodology does not make clear how proof of randomness can be ascertained for non-responsible drivers in two- and three-vehicle crashes. Police officers may similarly be as biased in their judgement of culpability for all crashes independent of the number of vehicles involved. Apparently, these authors did not challenge the assignment of culpability as such.

It is interesting to note that the low percentage of culpable crash involvement in most samples where such coding has been used (af Wåhlberg, 2009) must mean that people involved in making these judgements (police, company officials etc.) are not inclined to make a verdict of shared culpability. This might be due to insurance requirements or a psychological tendency 
to simplify information or for driver disciplinary reasons. It may also relate to how crash report forms are constructed. Despite this, the belief seems to persist that police officers' judgements about culpability are accurate, although it is not said according to which perspective (e.g. Brar, 2014).

Turning to the other side of behavioural culpability, the assumption that non-culpable drivers are a random sample of the driving population, this has been questioned (Dufournet, Lanoy, Martin \& Viallon, 2018). The argument made is apparently that non-culpable drivers may actually be different from the driving population. The behavioural culpability method, however, solves this, because the coding is not seen as set (which is an assumption made by the critics), but as an evolving tool which is to be revised until the result is indeed a random sample of the population. This approach should also answer the concerns voiced by Kim and Mooney (2016).

\subsection{Limitations}

The data in this paper, as well as in the former study, was for bus drivers. There is, however, no reason to believe that the proposed mechanism should be different for drivers of different vehicles. However, it should be noted that the percent culpable crashes might differ between populations. The behavioural culpability concept does not state anything about environmental effects. For example, the exact percent might differ between urban and rural conditions, for the same drivers, or between different types of vehicles. For example, heavy vehicles might be more difficult to drive, and the culpability percentage therefore higher. On the other hand, truck drivers are a selected and highly experienced population, which could predict the opposite effect.

The problem of sheer, random error of coding of culpability could not be analytically treated in this paper, although its presence would be a serious problem in this kind of research. If the coding of culpability has little validity even for the group of incidents deemed culpable, results will largely be meaningless. For authors who want to use culpability coding, it is therefore recommended that explicit, written rules be applied, like those outlined by Robertson and Drummer (1994). Furthermore, it is recommended that tests for the coding of culpability like the ones reported here are routinely used before attempting to investigate individual differences in traffic safety using crash databases.

It is possible that some drivers consistently drive on higher crash risk routes and time of day, while other drivers (with the same hours of exposure) typically drive on safer routes or at safer times. If this were the case then drivers with greater exposure can be expected to have more non-culpable crashes than drivers on low risk routes due to a mis-classification of exposure. The focus on this paper is to illustrate a technique for coding behavioural culpability, not tsting for differences between routes, but researchers should be aware of this eventuality.

One important limitation of the method of using and adjusting coding for behavioural culpability is that it should not be used with variables which use the same input data, as the risk of common method variance is high. For example, the criticism by Sanghavi (2013) regarding the use of responsibility analysis in mobile phone use and crash risk is apparently about this problem. In essence, if a factor such as whether a driver used a mobile phone at the time of the crash is known when culpability is assigned, then this cannot validly be used as a predictor. Predictors should be independent of the assignment of culpability.

\subsection{Conclusions}

The empirical part of this paper has again showed that different persons/organisations code culpability differently (at fault, responsibility, etc.) replicating previous findings (af Wåhlberg and Dorn, 2007). This has repercussions for the effects which can be calculated in the data 
(see Curry, Pfeiffer, Myers, Durbin \& Elliott, 2014, for similar results). What is a correct coding can only be ascertained if it is explicitly stated what the coding is meant to achieve. The aim of behavioural culpability coding is to increase effect sizes in individual differences in safety research with the aim of improving our capability of predicting accident involvement.

To achieve a correct coding, the manual shown in the Appendix has been written. If used, it will ensure that researchers who try to predict individual differences in safety will use the optimal dependent variable.

Given the present results and those in af Wåhlberg and Dorn (2007), the percent of culpable involvements in a given sample should be at least seventy percent. This general recommendation will depend on local differences of course (e.g., a fleet-based company with very high standards of safety).

It is also important to point out the theoretical properties of the concept of behavioural culpability as presented here. It is closely connected to the idea of accident proneness (af Wåhlberg, 2009, af Wåhlberg \& Dorn, 2009) and the prediction of accident involvement from individual differences variables. Most importantly, however, it is a hypothesis which is possible to falsify, a commodity which is scarce in traffic safety research.

\section{Acknowledgements}

This research did not receive any specific grant from funding agencies in the commercial, public or not-for-profit sectors. The data was provided by a major British bus company.

\section{References}

Asbridge, M., Brubacher, J.R., \& Chan, H. (2013). Cell phone use and traffic crash risk: a culpability analysis. International Journal of Epidemiology, 42, 259-267.

Besharati, M. M., \& Kashani, A. T. (2018). Factors contributing to intercity commercial bus drivers' crash involvement risk. Archives of Environmental \& Occupational Health, 73, $243-$ 250. DOI: $10.1080 / 19338244.2017 .1306478$

Blom, D. H., Pokorny, M. L., \& van Leeuwen, P. (1987). The role of age and experience in bus drivers' accidents. International Journal of Epidemiology, 16, 35-43.

Brar, S. S. (2014). Estimating the over-involvement of suspended, revoked and unlicensed drivers as at-fault drivers in California fatal crashes. Journal of Safety Research, 50, 53-58.

Brubacher, J., Chan, H., \& Asbridge, M. (2012). Development and validation of a crash culpability scoring tool. Traffic Injury Prevention, 13, 219-229. DOI:

$10.1080 / 15389588.2011 .645383$

Carr, B. R. (1969). A statistical analysis of rural Ontario traffic accidents using induced exposure data. Accident Analysis and Prevention, 5, 343-357.

Chandraratna, S., \& Stamatiadis, N. (2009). Quasi-induced exposure method: Evaluation of not-at-fault assumption. Accident Analysis \& Prevention, 41, 308-313.

Chipman, M. L., MacGregor, C. G., Smiley, A. M., \& Lee-Gosselin, M. (1992). Time vs. distance as measures of exposure in driving surveys. Accident Analysis and Prevention, 24, 679-684. 
Chipman, M. L., MacGregor, C. G., Smiley, A. M., \& Lee-Gosselin, M. (1993). The role of exposure in comparisons of crash risk among different drivers and driving environments. Accident Analysis and Prevention, 25, 207-211.

Cooper, P. J., Meckle, W., \& Andersen, L. (2010). The efficiency of using non-culpable crashclaim involvements from insurance data as a means of estimating travel exposure for road user sub-groups. Journal of Safety Research, 41, 129-136.

Council, F. M., Harkey, D. L., Khattak, A. J., \& Mohamedshah, Y. M. (2003). Examination of fault, unsafe driving acts, and total harm in car-truck collisions. Transportation Research Record, 1830, 63-71.

Curry, A. E., Pfeiffer, M. R., \& Elliot, M. R. (2017). Compliance with and enforcement of graduated driver licensing restrictions. American Journal of Preventive Medicine, 52, 47-54.

Curry, A. E., Pfeiffer, M. R., Myers, R. K., Durbin, D. R. \& Elliot, M. R. (2014). Statistical implications of using moving violations to determine crash responsibility in young driver crashes. Accident Analysis and Prevention, 65, 28-35.

Dionne, G., Desjardins, D., Laberge-Nadeau, C., \& Maag, U. (1995). Medical conditions, risk exposure, and truck drivers' accidents: An analysis with count data regression models. Accident Analysis and Prevention, 27, 295-305.

Dorn, L., \& af Wåhlberg, A. E. (2008). Work related road safety: An analysis based on UK bus driver performance. Risk Analysis: An International Journal, 28, 25-35.

Dufournet, M., Lanoy, E., Martin, J. L., \& Viallon, V. (2018). Causal inference to formalize responsibility analysis in road safety epidemiology.

$\underline{\text { arXiv: } 1607.03775}$

Goh, K., Currie, G., Sarvi, M., \& Logan, D. (2014). Factors affecting the probability of bus drivers being at fault in bus-involved accidents. Accident Analysis and Prevention, 66, 20-26.

Jiang, X. \& Lyles, R.W. (2010). A review of the validity of the underlying assumptions of quasi-induced exposure. Accident Analysis and Prevention, 40, 1352-1358.

Häkkinen, S. (1979). Traffic accidents and professional driver characteristics: A follow-up study. Accident Analysis and Prevention, 11, 7-18.

Kim, J. H., \& Mooney, S. J. (2016).The epidemiologic principles underlying traffic safety study designs. International Journal of Epidemiology, 45, 1668-1675.

https://doi.org/10.1093/ije/dyw172

Ma, L. \& Yan, X. (2014). Examining the nonparametric effect of drivers age in rear-end accidents through an additive logistic regression model. Accident Analysis and Prevention, 67, 129-136. 
Peck, R. C. (1993). The identification of multiple accident correlates in high risk drivers with specific emphasis on the role of age, experience and prior traffic violation frequency. Alcohol, Drugs and Driving, 9, 145-166.

Pelz, D. C., \& Schuman, S. H. (1971). Are young drivers really more dangerous after controlling for exposure and experience? Journal of Safety Research, 3, 68-79.

Robertson, M. D., \& Drummer, O. H. (1994). Responsibility analysis: a methodology to study the effects of drugs in driving. Accident Analysis and Prevention, 26, 243-247.

Sabey, B.E \& Taylor, H. (1980). The known risks we run: The Highway. TRRL Report 567. Crowthorne: Transport and Road Research Laboratory.

Salmi, L. R., Orriols, L., \& Lagarde, E. (2014). Comparing responsible and non-responsible drivers to assess determinants of road traffic collisions: time to standardise and revisit. Injury Prevention, 20, 380-386. doi:10.1136/injuryprev-2013-041143

Sanghavi, P. (2013). Commentary: Culpability analysis won't help us understand crash risk due to cell phones. International Journal of Epidemiology, 42, 267-269.

Vaa, T. (2014). ADHD and relative risk of accidents in road traffic: A meta-analysis. Accident Analysis and Prevention, 62, 415-425.

Vujanic', M., Antic', B., Pešic', D., \& Savic'evic', M. (2016). Testing the psychophysical characteristics of professional drivers - Can we identify unsafe drivers? Transportation Research Part F, 42, 104-116.

West, R. (1997). Accident Script Analysis. TRL Report 274. Crowthorne: Transport Research Laboratory.

af Wåhlberg, A. E. (2002). Characteristics of low speed accidents with buses in public transport. Accident Analysis and Prevention, 34, 637-647. https://doi.org/10.1016/S0001$\underline{4575(01) 00063-X}$

af Wåhlberg, A. E. (2003). Some methodological deficiencies in studies on traffic accident predictors. Accident Analysis and Prevention, 35, 473-486.

http://dx.doi.org/10.1016/S0001-4575(02)00025-8

af Wåhlberg, A. E. (2006). Driver celeration behavior and the prediction of traffic accidents. International Journal of Occupational Safety and Ergonomics, 12, 281-296.

af Wåhlberg, A. E. (2009). Driver Behaviour and Accident Research Methodology; Unresolved Problems. Farnham: Ashgate.

af Wåhlberg, A. E. (2018). The effect of driver improvement interventions on crash involvement; has it been under-estimated? Transportation Research Part F: Traffic Psychology and Behaviour, 54, 349-356. doi.org/10.1016/j.trf.2018.02.027

af Wåhlberg, A. E. (forthcoming). Accuracy of conversion formulae for effect sizes. 
af Wåhlberg, A. E., Barraclough, P., \& Freeman, J. (2015). The Driver Behaviour Questionnaire as accident predictor; a methodological re-meta-analysis. Journal of Safety Research, 55, 185-212. DOI: 10.1016/j.jsr.2015.08.003

af Wåhlberg, A. E., Barraclough, P., \& Freeman, J. (2016). Personality versus traffic accidents; meta-analysis of real and method effects. Transportation Research Part F: Traffic Psychology and Behaviour, 44, 90-104. http://dx.doi.org/10.1016/j.trf.2016.10.009

af Wåhlberg, A. E., \& Dorn, L. (2007). Culpable versus non-culpable traffic accidents; what is wrong with this picture? Journal of Safety Research, 38, 453-459.

af Wåhlberg, A. E., \& Dorn, L. (2009). Bus driver accident record; the return of accident proneness. Theoretical Issues in Ergonomics Science, 10, 77-91. 
Appendix: Coding for behavioural culpability

A step-by-step manual for testing the correctness of a criterion for behavioural culpability and actual coding, and thereby optimizing your effect sizes when predicting individual differences in accident involvement record.

Prerequisites:

a) Crash investigation data with written information and preferably photos about how and where the incident happened, from a known sample/population, for a time period which yields a mean number of crashes of at least 0.5 per driver.

b) Objective driver information (predictor variables) of some kind which is known to correlate with crash involvement (sex, age, experience, type of license, intoxication etc.) on all drivers in the sample, including those without crashes, is also needed.

c) Exposure data of some type (mileage or hours of driving). Exposure must be held constant, as differences on this variable will create an artificial correlation between crash variables. If no metric variable is available, non-culpable crashes can be used as a measure of exposure, but only at a group level.

\section{Method:}

1. Form a criterion for behavioural culpability (i.e. what kind of actions can be considered to be decisive for a judgement of culpable involvement). Specify this in written form (or even better, in an algorithm; Asbridge, Brubacher \& Chan, 2013; Brubacher, Chan \& Asbridge, 2012). Test the inter-rater reliability (no exact guidance for an acceptable level of reliability is given here).

2. Apply the criterion to the crash involvements available and code each drivers' crash involvements as culpable or non-culpable (weights should not be used, or they should be tested in a separate study, because it is not known what kind of weights should be applied). Culpability can be shared between road users. Enter the number of (partially and fully) culpable and non-culpable crashes for each driver in two columns.

3. Calculate the effects and compare these to the expected values or differences presented below.

a) The percent culpable involvements (as compared to all). Should be $>50$ and $<100 \%$.

b) Run a correlation between culpable and non-culpable crash involvements. If your criterion and coding is correct, there should be no correlation $(\mathrm{r}<.1$, regardless of significance) between culpable and non-culpable crash involvements. Larger correlations indicate erroneous coding.

c) Run correlations between all crashes and your predictor variables, preferably experience. If you do not get a significant correlation (CIs can also be used) for all crashes, increase your sample, or the time period for canvassing crashes, or use different predictors.

If you get a significant correlation for all crash involvements, go ahead with the predictor variable and correlate this with the culpable and non-culpable variables. The effect should be larger for the culpable crash involvements as compared to all crash involvements (exposure held constant). If it is not, this indicates erroneous coding.

Non-culpable crash involvements should not correlate $(<.1)$ with any predictor when exposure has been controlled for (either as crashes/exposure unit or in a partial correlation). If they do, this indicates erroneous coding of culpable crashes as non-culpable. 
d) If you get a significant correlation for one or more predictor variables against culpable crash involvements, split the sample into three groups (drivers with no crashes, drivers with non-culpable crashes only, and other (i.e. drivers with culpable and possibly non-culpable crashes) and compare the means on the significant predictor variable(s) between the groups. The group of drivers with non-culpable crashes only (no culpable) should be similar to the group of drivers with no crashes (no difference on experience, for example), while the third group (drivers with culpable crash involvements) should differ from the other two (less experience, for example). A test of significance can be applied, or CIs.

If you do not get these effects, this indicates erroneous coding. If the non-culpable group is different from the no crash group, in the direction of the culpable group, culpable crash involvements have been coded as non-culpable. If the culpable group is not different from the other two, non-culpable crashes have been coded as culpable.

e) Compare the drivers with non-culpable crash involvements and those with culpable involvements (overlapping groups) with the population values, if available on your significant predictor variables.

Drivers with non-culpable crashes should not differ from the population values, while drivers with culpable involvements should differ in the same direction as the effect for all crashes (being younger, less experienced etc.). Please note that the group of drivers with non-culpable crashes overlaps with drivers with non-culpable crashes only.

If the group of drivers with non-culpable crashes only is similar to the group without crashes on the predictor variables used, but there is a correlation between culpable and non-culpable crash involvements, your criterion is likely too harsh (probably yielding more than 75 percent culpable crash involvements).

If the group with non-culpable crash involvements only is different from the group without crashes, and similar to the third group, your criterion is too lenient (probably yielding less than 70 percent culpable involvements).

If the drivers with non-culpable involvements differ from the population, this indicates that the criterion is too lenient (truly culpable crash involvements have been coded as nonculpable).

4. If you get indications of erroneous coding, change your criterion; re-code the crash involvements and re-run steps 1-3. It is probably not necessary to re-code all cases, only one of the crash variables. Which one is chosen (culpable or non-culpable) depends upon the pattern of effects. Also, it is probable that there are a few cases which were deemed uncertain in the first round of analysis. If these are moved to the other category, the problem should at least be reduced.

5. If steps 1-4 are run several times, an optimum effect level should be reached, probably at about 75 percent culpable crash involvements. On either side of this percentage, effects on the predictors should be smaller for the culpable variable.

6. When the optimum has been found, the criterion can be used for coding crash involvements in studies on individual differences in road safety in the type of population in which it has been tested. The result will be an optimal effect for the predictors (given all other influences on effect size being equal, see af Wåhlberg, 2009, for further guidelines about how to optimize your effect size). The further use of the thus formed rules can be seen as crossvalidation of the criterion. Always use all and culpable accidents in parallel when investigating safety. 
Notes:

The effect sizes noted in this text are rough estimates based upon currently available results. They are also influenced by the variance in the accident variables, guidelines for which will hopefully be published in the future.

When controlling for exposure, be sure to check for outliers, as these are easily created by low-mileage drivers.

The predictor variables used should preferably not be self-reported, as this method inserts systematic error variance that can have effects which cannot be foreseen.

Variables which have been used in determining culpability should not be sued as predictors. In a future development of the method, it will be possible to calculate the percent of misclassified crash involvements from the effect sizes between culpable and non-culpable crash involvements. 


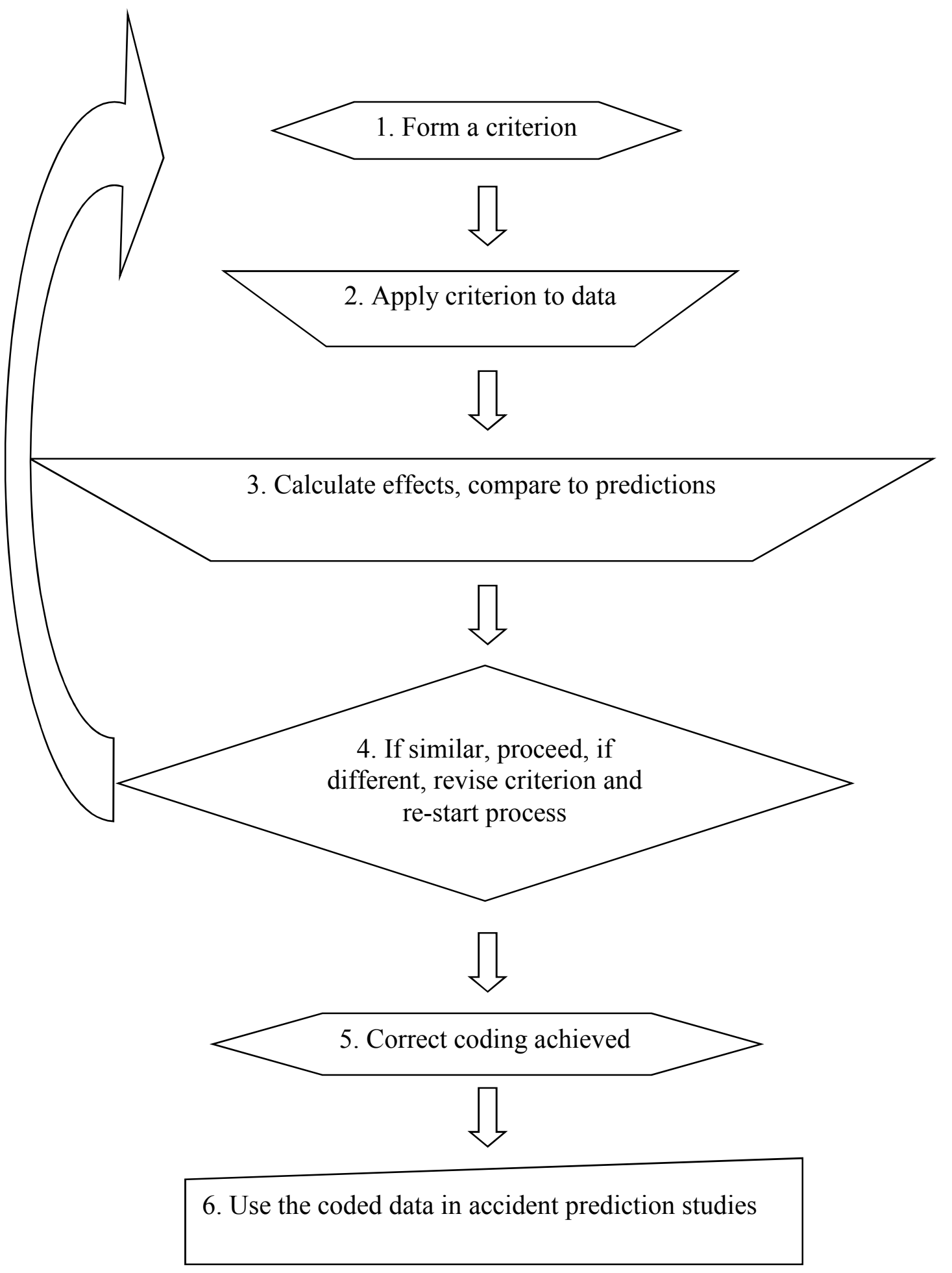

Figure 1 Flowchart for the process of testing the correctness of culpability coding, as described in the Appendix. 
2018-12-03

\title{
Behavioural culpability for traffic accidents
}

\author{
Dorn, Lisa
}

Elsevier

Dorn L, af Wåhlberg AE. (2019) Behavioural culpability for traffic accidents. Transportation

Research Part F: Traffic Psychology and Behaviour, Volume 60, January 2019, pp. 505-514

https://doi.org/10.1016/j.trf.2018.11.004

Downloaded from Cranfield Library Services E-Repository 